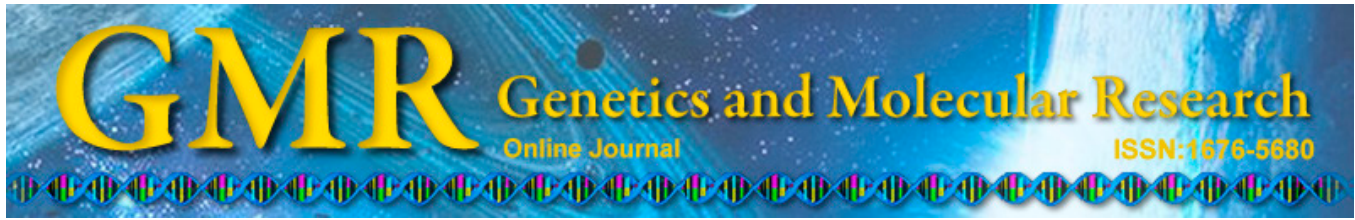

\title{
Identification of molecular markers associated with fruit traits in olive and assessment of olive core collection with AFLP markers and fruit traits
}

\author{
M. Ipek ${ }^{1}$, M. Seker ${ }^{2}$, A. Ipek ${ }^{1}$ and M.K. Gul ${ }^{3}$ \\ ${ }^{1}$ Department of Horticulture, Faculty of Agriculture, Uludag University, \\ Bursa, Turkey \\ ${ }^{2}$ Department of Horticulture, Faculty of Agriculture, Sirnak University, \\ Sirnak, Turkey \\ ${ }^{3}$ Sales and Marketing Manager, EuroChem Agro, Istanbul, Turkey \\ Corresponding author: M. Ipek \\ E-mail:msipek@uludag.edu.tr
}

Genet. Mol. Res. 14 (1): 2762-2774 (2015)

Received February 25, 2014

Accepted June 30, 2014

Published March 31, 2015

DOI http://dx.doi.org/10.4238/2015.March.31.6

\begin{abstract}
The purpose of this study was to characterize olive core collection with amplified fragment length polymorphism (AFLP) markers and fruit traits and to determine AFLP markers significantly associated with these fruit characters in olive. A total of 168 polymorphic AFLP markers generated by five primer combinations and nine fruit traits were used to characterize relationships between 18 olive cultivars. Although all olive cultivars were discriminated from each other by either AFLP markers $(<0.75$ similarity level) or fruit traits, clustering based on the AFLP markers and fruit traits was not significantly correlated $(\mathrm{r}=0.13)$. Partial clustering of olive cultivars by AFLP markers according to their geographical origin was observed. Associations of AFLP markers with fruits were determined using a multiple-regression analysis with stepwise addition of AFLP markers.
\end{abstract}


Significant associations between eight AFLP markers and fruit traits were identified. While five AFLP markers demonstrated significant negative correlation with fruit and stone weight, width and length and total polyphenols $(\mathrm{P}<0.05)$, three AFLP markers displayed significant positive correlation with $\alpha$-tocopherol and $\gamma$-tocopherol $(\mathrm{P}<0.01)$. This is the first report on the association of molecular markers with fruit traits in olive. Molecular markers associated with morphological and agronomic traits could be utilized for the breeding of olive cultivars. However, the association power of these markers needs to be confirmed in larger populations, and highly correlated markers should then be converted to PCR-based DNA markers such as sequence-characterized amplified region markers for better utilization.

Key words: Olive (Olea europaea L.); Molecular marker association; Fruit traits; AFLP; Genetic relationships

\section{INTRODUCTION}

Olive trees (Olea europaea L.) originated in the Mediterranean basin and have been cultivated since ancient times in this region (Besnard et al., 2001). There is a considerable amount of genetic variation in olive, although it is a clonally propagated fruit crop and has very long life. About 1200 olive cultivars have been documented worldwide (Bartolini et al., 1998). Determination of genetic relationships between olive genotypes has become an important issue for the breeding of the new cultivars with improved oil yield and other agronomic traits, association of molecular markers with important traits, conservation of genetic recourses as diverse as possible, and germplasm management.

Genetic diversity between olive cultivars has been determined using various approaches. Traditionally, morphological characters have been utilized to characterize olive cultivars and genotypes (Cantini et al., 1999; Rotondi et al., 2003; Taamalli et al., 2006). Fruit characters are the most important morphological descriptors for the differentiation of olive cultivars since they display great differences between the olive cultivars and are considered more reliable than other morphological traits due to their relatively high heritability (Fendri et al., 2010). Although the genetic basis of many morphological and agronomic traits has not been yet determined in olives, environmental influences on these characters can lead to misidentification of olive genotypes and cultivars. In addition, homonyms, synonyms and misnaming have been reported to be common in olive (Fendri et al., 2010; Ipek et al., 2012). Recently, different types of molecular markers have been used to reveal genetic diversity between olive genotypes. Randomly amplified polymorphic DNA (RAPD) markers were the first molecular markers used to identify olive cultivars (Bogani et al., 1994). Later, amplified fragment length polymorphism (AFLP) markers were found to be useful for the assessment of genetic diversity between olive cultivars, wild genotypes, and Olea species (Angiolillo et al., 1999; Owen et al., 2005; Ercisli et al., 2009). Simple sequence repeat (SSR) markers are another choice of marker technology for the characterization of olive genotypes and a considerable number of SSR markers have been developed for the olive genome in recent years (e.g., Rallo et al., 2000; Sefc et al., 2000; Ipek et al., 2009).

AFLP is a polymerase chain reaction (PCR)-based DNA marker technology (Vos et al., 1995), and it does not require prior sequence information for marker development (Tohme 
et al., 1996). AFLP markers have been preferred for various molecular studies, including genetic diversity assessment, genetic mapping and cultivar fingerprinting, because of their effectiveness, reproducibility and high multiplex ratio in a single reaction (Vos et al., 1995; Tohme et al., 1996; Angiolillo et al., 1999; la Rosa et al., 2003; Owen et al., 2005; Ipek et al., 2003, 2005, 2008). In a comparative genetic diversity analysis of olive genotypes using AFLP, SSR and RAPD markers, AFLPs were found to be the most efficient marker system although expected heterozygosity was the lowest for AFLPs. In addition, dendrogram topologies for all tree marker technologies were found to be very similar (Belaj et al., 2003). Similarly, high concordance between the dendrograms of AFLP and expressed sequence tag-SSR markers (Ipek et al., 2015) and between AFLP and RAPD markers ( $r=0.96)$ (Ipek et al., 2003) was determined.

Recently, some studies reported a correlation between morphological and molecular data for the determination of genetic relationships between olive cultivars (Taamalli et al., 2006; D'Imperio et al., 2011), but in several other studies conducted on olive, genetic diversity assessment of morphological and molecular data was not significantly correlated (Corrado et al., 2009; Rao et al., 2009; Belaj et al., 2011). However, there is no report on the association of molecular markers with any morphological and agronomic fruit traits in olive to our knowledge. For breeding and other genetic studies, molecular markers linked to traits of interest are highly desired in plants. The use of molecular markers in the selection program can accelerate breeding studies in olive, which is considered one of the fruit crops with the longest juvenile period (Rao et al., 2009).

The objectives of this study were 1) to characterize an olive core collection consisting of commercial varieties grown in Turkey and other countries with AFLP markers and fruit traits, 2) to compare AFLP marker and fruit trait data for the estimation of genetic relationships, and 3) to determine AFLP markers significantly associated with fruit characters in olive.

\section{MATERIAL AND METHODS}

\section{Plant material}

A total of 18 olive cultivars maintained on the Experimental Plot of the Olive Production Station of the Ministry of Agriculture and Rural Affairs, Balikesir, Turkey, were used for analyses (Table 1). The trees of each accession were more than 20 years old and under optimum cultivation conditions. Since all olive cultivars have been maintained in the same experimental plot with three replicates, the variation due to the environmental factors such as temperature, light and soil that influence morphological and agronomic traits can be considered negligible among the cultivars.

\section{Fruit sampling}

Fruits were collected from three trees of each cultivar on the same day. A total of 100 fruit samples from each tree were picked when $75 \%$ of the fruits were colored pink/purple on trees. Fruits were harvested from the beginning of December to the end of January for two consecutive growing seasons. The optimum maturity stage of olive cultivars was determined by grouping the olives according to skin and flesh color, and then applying maturity index equitation as indicated by Boskou (2002). 
Characterization of olive core collection

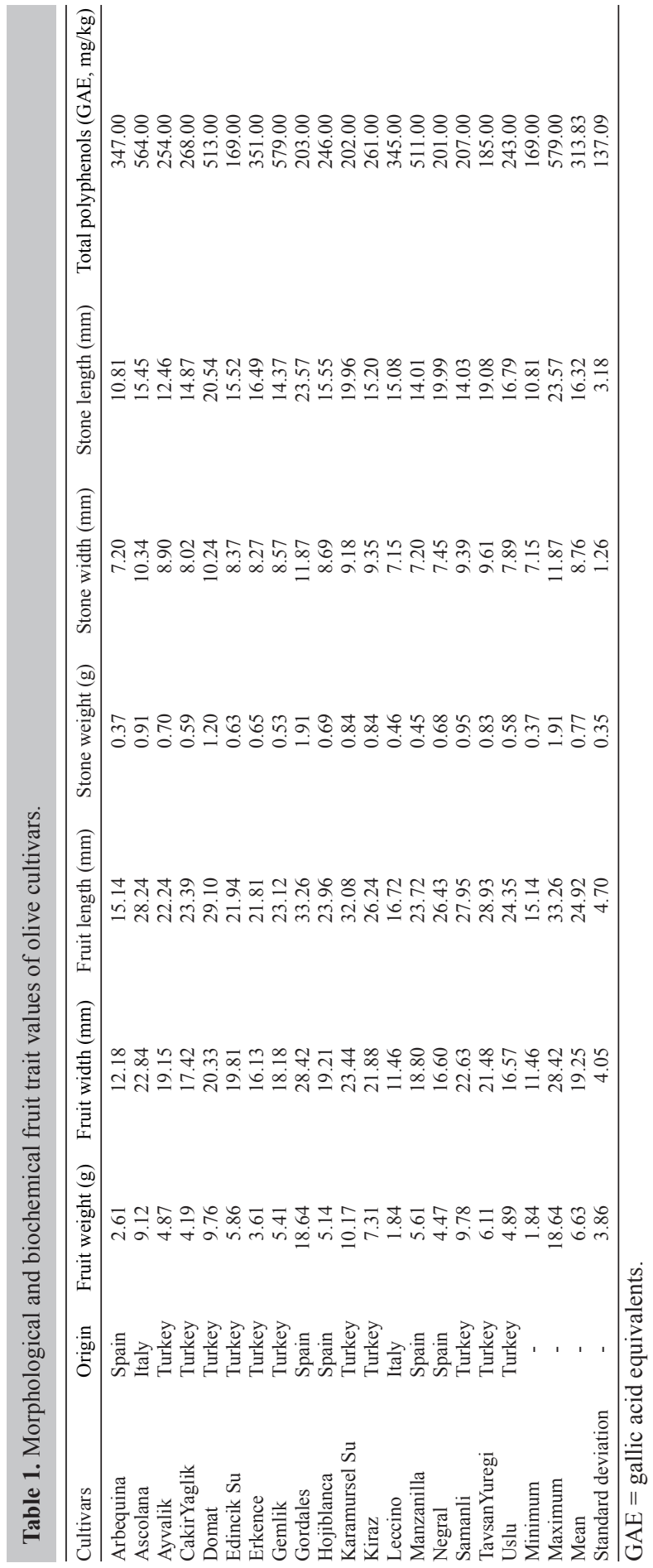


The maturity index of the analyzed cultivars varied between 2.40 and 3.80 (data not shown). Morphological fruit characteristics, including fruit weight, fruit width, fruit length, stone weight, stone width, and stone length, and biochemical fruit characteristics, including total polyphenols, $\alpha$-tocopherol and $\gamma$-tocopherol, were determined from harvested fruit samples.

\section{Evaluation of morphological and biochemical fruit characteristics}

Morphological fruit traits were evaluated from three replicates per cultivar. Fruit weight $(\mathrm{g})$, fruit width $(\mathrm{mm})$, fruit length $(\mathrm{mm})$, stone weight $(\mathrm{g})$, stone width $(\mathrm{mm})$, and stone length $(\mathrm{mm})$ were measured from 30 fruits in each replicate. For biochemical evaluations, olive oil was extracted from harvested fruits as previously described by Şeker et al. (2008). Total polyphenols of extracted oil samples were measured by utilizing the Folin-Ciocalteu colorimetric method, and the results were determined as gallic acid equivalents (GAE) (Gutfinger, 1981). $\alpha$-tocopherol and $\gamma$-tocopherol contents of olive oil were presented in a previous study (Şeker et al., 2008) and included in this study for the analyses of genetic relationships and AFLP marker association.

\section{AFLP analysis}

DNA samples were extracted from $20 \mathrm{mg}$ freeze-dried and powdered leaf samples by using the DNeasy Plant Mini kit (Qiagen, Germany). The concentration of each DNA sample was measured using a Qubit Fluorometer (Invitrogen, USA) and adjusted to $30 \mathrm{ng} / \mu \mathrm{L}$. AFLP analyses were carried out by following the manufacturer protocol using the AFLP kit number I (Invitrogen). Five selective amplification primer combinations were used to reveal polymorphisms among the olive cultivars (Table 2). EcoRI primers used at selective amplification step were labeled with LI-COR infrared dye either at 700 or $800 \mathrm{~nm}$ (LI-COR, USA). PCR was performed by using a GenAmp 2720 Thermal Cycler (Applied Biosystems, USA). The PCR products diluted in an equal amount of formamide-loading buffer were denatured at $94^{\circ} \mathrm{C}$ for 4 min and immediately placed on ice. The denatured PCR products were separated on $6 \%$ denaturing polyacrylamide sequencing gels by running at $30 \mathrm{~W}$ for 5 to $6 \mathrm{~h}$ with a LI-COR 4300 automated sequencer system.

\section{Data analyses}

Unambiguous polymorphic DNA bands in each AFLP primer combination were manually scored as present (1) or absent (0) to obtain binary data. Genetic similarity matrix for AFLP data was calculated using the Dice coefficient (Dice, 1945) while Euclidean distance matrix was calculated for fruit traits (Sneath and Sokal, 1973). Unweighted pair group method with arithmetic averages (UPGMA) dendrograms were constructed using these matrices and the NTSYSpc v.2.21 program (Exeter Software, USA). Principal component analysis (PCA) was carried out according to the procedure described in the NTSYSpc program. Heterozygosity and the polymorphic information content (PIC) values for AFLP markers were calculated using PIC Calculator Extra (http://www.genomics.liv.ac.uk/animal/pic.html).

\section{Statistical analyses}

Stepwise multiple-regression analysis (MRA) was performed to determine the association 
between the molecular data (independent variable) and phenotypic data (dependent variable). To identify the informative markers associated with six phenotypic and three biochemical fruit traits, MRA was conducted using the "linear regression analysis" method with "stepwise" option of SPSS v.20. The model of the analysis was $Y=a+b 1 m 1+b 2 m 2+\ldots+b j m j+\ldots+b n m n+d$ $+e$, where $Y$ is the cultivar mean for a quantitative trait (dependent variable) and $m j$ is the AFLP marker (independent variable) (Virk et al., 1996). bj represents the partial regression coefficients that specify the empirical relationships between quantitative traits and AFLP markers, $d$ is the accession residual left after regression, and $e$ is the random error of $Y$ that includes environmental variation. To select independent variables for regression equation, probability of $\mathrm{F}$ between 0.045 and 0.099 for entry and removal, respectively, was used (Affifi and Clarck, 1984; Kar et al., 2008). $R^{2}$ is the square of $R$, which is the multiple correlation coefficient. Markers identified by MRA were tested again independently with linear curve fitting using linear models to confirm the significance of $\beta$-statistics. Beta can be defined as the standardized regression coefficient and equals $B S_{x} / S_{y}$, where $B$ is the regression coefficient, and $S x$ and $S y$ are the standard deviation of independent (x) and dependent (y) variables (Affifi and Clarck, 1984; Kar et al., 2008). The Student $t$-test was performed to test significance between mean trait estimates of genotypes where specific markers were present and absent. Markers showing significant regression values were considered as associated with the respective traits. Pearson correlations between fruit traits were calculated using the SPSS program with the two-tailed option checked. Descriptive statistical values were also calculated with the SPSS program.

\section{RESULTS}

\section{Assessment of olive cultivars with AFLP markers}

Five AFLP primer combinations revealed 168 unambiguous polymorphic markers among the 18 olive cultivars. Polymorphic markers ranged from 23 for EACC/MCTT primer combination to 43 for EACA/MCAT primer combination, with an average of 34.60 markers per primer combination and sizes of polymorphic markers varied between 60 to $610 \mathrm{bp}$. Both PIC values and heterozygosity of AFLP markers ranged from 0.95 to 0.97 (Table 2).

Table 2. Number of polymorphic AFLP markers, size range of polymorphic markers, heterozygosity $\left(H_{\mathrm{E}}\right)$ and polymorphic information content (PIC) values for each primer combination.

\begin{tabular}{|c|c|c|c|c|}
\hline Pimer combinations & Polymorphic markers & Estimated size range (bp) & $H_{\mathrm{E}}$ & PIC \\
\hline EAGG/MCTC & 34 & $80-340$ & 0.96 & 0.96 \\
\hline EAGG/MCAA & 40 & $83-585$ & 0.97 & 0.97 \\
\hline EACA/MCAT & 43 & $60-610$ & 0.97 & 0.97 \\
\hline EACC/MCTA & 28 & $102-402$ & 0.96 & 0.96 \\
\hline EACC/MCTT & 23 & $75-498$ & 0.95 & 0.95 \\
\hline
\end{tabular}

The UPGMA dendrogram constructed using the similarity matrix of the Dice coefficient (Dice, 1945) clustered olive cultivars into two major groups at about 55\% similarity (Figure 1). Cultivars in each major group further clustered into two subgroups. One of the major groups in the dendrogram included only olive cultivars (Domat, Ayvalik, Samanli, Erkence, Cakir Yaglik, Uslu, Edincik Su, Kiraz) originating from Turkey. Turkish cultivars, Gemlik and Karamursel Su, clustered in a subgroup of the other major group with olive cul- 
tivars from Italy (Leccino) and Spain (Arbequina). Another Turkish cultivar, Tavsan Yuregi, grouped with cultivars from Spain (Negral, Manzanilla, Hojiblanca, Gordales) and Italy (Ascolana) in the other subgroup (Table 1 and Figure 1).
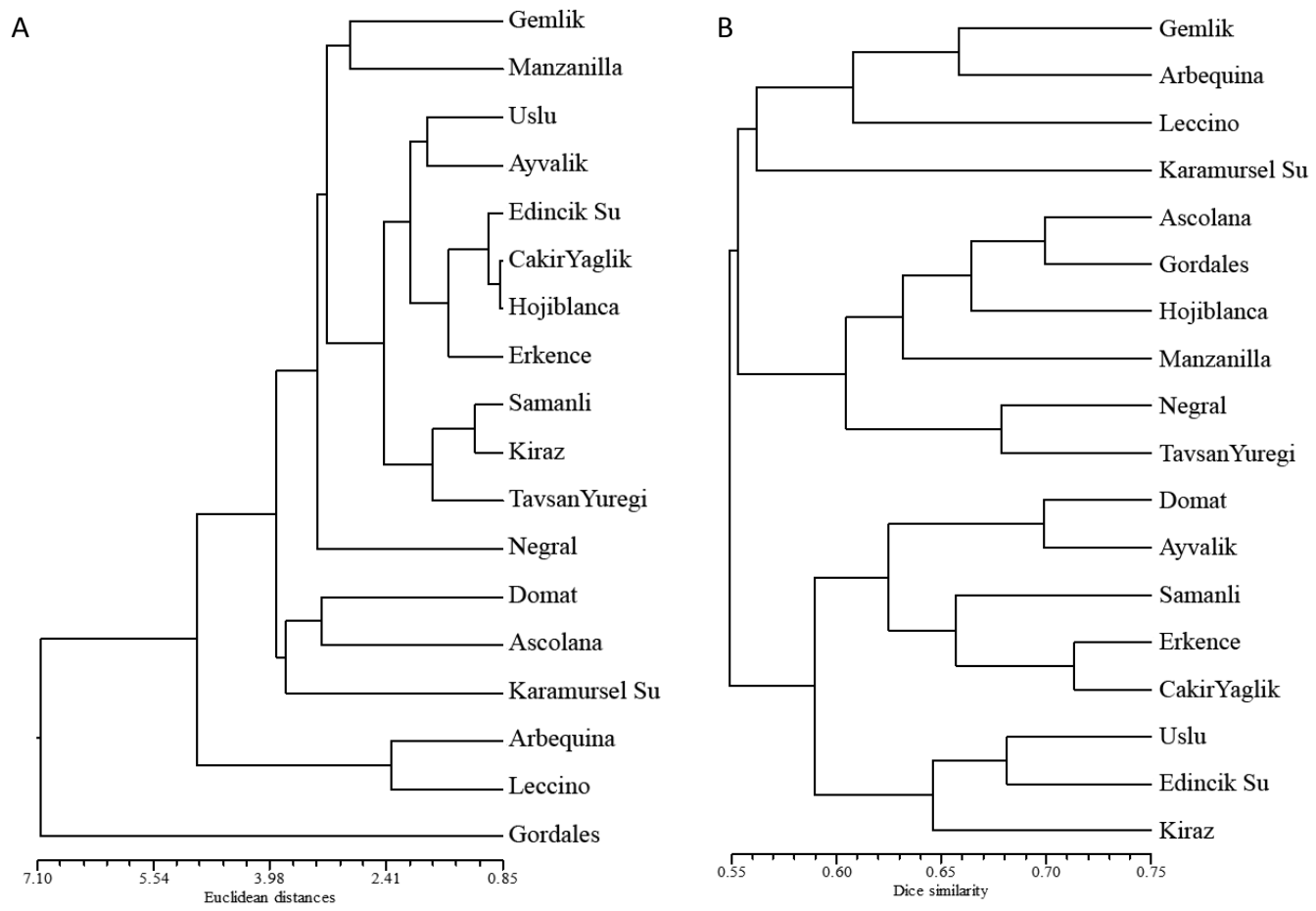

Figure 1. UPGMA dendrograms based on A. fruit traits and B. AFLP markers.

\section{Characterization of olive cultivars using fruit traits}

In terms of fruit characters, there is a great amount of variation among the 18 olive cultivars maintained at core collection (Table 1). The fruit weight of olive cultivars ranged from 1.84 to $18.64 \mathrm{~g}$, fruit width from 11.46 to $28.42 \mathrm{~mm}$, and fruit length from 15.14 to 33.26 $\mathrm{mm}$. The stone weight varied from 0.37 to $1.91 \mathrm{~g}$, stone width from 7.15 to $11.87 \mathrm{~mm}$, and stone length from 10.81 to $23.57 \mathrm{~mm}$ (Table 1). The highest total polyphenol content was observed in Gemlik (579 GAE mg/kg) and followed by Ascolana (564 GAE mg/kg) and Domat (513 GAE mg/kg), while the lowest total polyphenol content was determined in Edincik Su (169 GAE mg/kg). The average values for $\alpha$-tocopherol and $\gamma$-tocopherol contents of olive cultivars are available in a previously published study (Şeker et al., 2008).

The UPGMA dendrogram constructed using the Euclidean distance matrix of fruit traits clustered olive cultivars into six distinct groups (Figure 1). The most distinct group included only the cultivar Gordales, which had the highest fruit weight, fruit size, stone weight, and stone size among the olive cultivars characterized (Table 1 and Figure1). The second distinct group contained the closely clustered cultivars Arbequina and Leccino. These two cultivars also grouped together in the AFLP dendrogram (Figure 1) and had the lowest values of morphologi- 
cal fruit traits among the olive cultivars analyzed. The third distinct group had Domat, Ascolana and Karamursel Su cultivars with relatively smaller fruit weight, fruit size, stone weight, and stone size than Gordales. The cultivar Negral clustered as the fourth distinct group in the dendrogram with medium fruit size parameters. Another group in the dendrogram consisted of Gemlik and Manzanilla olive cultivars with relatively smaller fruit size than the cultivars in the first and second groups but with higher total polyphenol content. The remaining nine olive cultivars loosely clustered in the fifth group with no distinctive fruit characteristics. The Mantel test between the matrices of AFLP markers and fruit traits revealed low correlation $(r=0.13)$ between these matrices for the estimation of genetic relationships between the olive cultivars.

PCA based on phenotypic and biochemical data did not group olive cultivars with clear separation (Figure 2). However, Gordales separated from the rest of the cultivars by having the largest fruits, while Arbequina and Leccino with the smallest fruit also differed from other cultivars. On the other hand, closely clustered cultivars in UPGMA analysis were also grouped together by PCA.

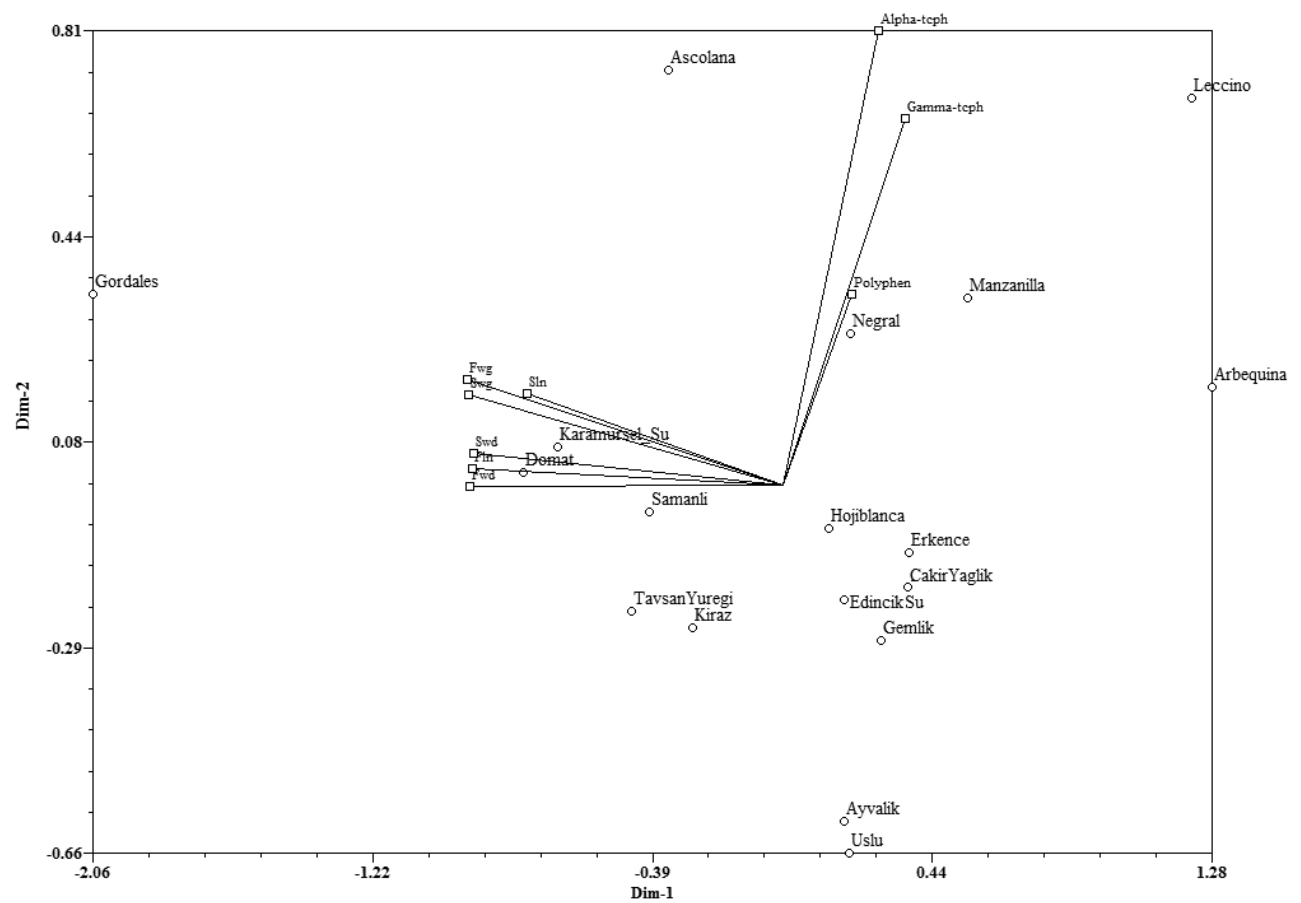

Figure 2. PCA analysis based on nine fruit traits. Alpha-tcph $=\alpha$-tocopherol; Gamma-tchp $=\gamma$-tocopherol; Fwg = fruit weight; Fwd = fruit width; Fln = fruit length; Swg = stone weight; Swd = stone width; Sln = stone length; Polyphen $=$ Polyphenols.

The Pearson correlation coefficients demonstrated significant and high positive correlations between fruit traits. The highest correlation (0.94) was obtained between fruit weight and stone weight and the lowest one (0.56) was between fruit width and stone length. On the other hand, low correlations between morphological and biochemical fruit traits and within the biochemical values were observed (Table 3). 
Table 3. Pearson correlation values between fruit traits.

\begin{tabular}{|c|c|c|c|c|c|c|c|c|}
\hline & $\begin{array}{l}\text { Fruit weight } \\
\text { (g) }\end{array}$ & $\begin{array}{l}\text { Fruit width } \\
(\mathrm{mm})\end{array}$ & $\begin{array}{l}\text { Fruit length } \\
(\mathrm{mm})\end{array}$ & $\begin{array}{l}\text { Stone weight } \\
\text { (g) }\end{array}$ & $\begin{array}{l}\text { Stone width } \\
(\mathrm{mm})\end{array}$ & $\begin{array}{l}\text { Stone length } \\
\text { (mm) }\end{array}$ & $\begin{array}{l}\text { Total polyphenols } \\
\text { (GAE, } \mathrm{mg} / \mathrm{kg} \text { ) }\end{array}$ & $\begin{array}{l}\alpha \text {-tocopherol } \\
(\mathrm{mg} / \mathrm{kg})\end{array}$ \\
\hline Fruit width & $0.90^{* *}$ & & & & & & & \\
\hline Fruit length & $0.83 * *$ & $0.80 * *$ & & & & & & \\
\hline Stone weight & $0.94 * *$ & $0.82 * *$ & $0.78 * *$ & & & & & \\
\hline Stone width & $0.88^{* *}$ & $0.88^{* *}$ & $0.79 * *$ & $0.91 * *$ & & & & \\
\hline Stone length & $0.66^{* *}$ & $0.56^{*}$ & $0.77^{* *}$ & $0.74 * *$ & $0.58^{*}$ & & & \\
\hline Total polyphenols & ls -0.10 & -0.17 & -0.16 & -0.17 & -0.03 & -0.24 & & \\
\hline$\alpha$-tocopherol & -0.15 & -0.23 & -0.20 & -0.14 & -0.28 & -0.08 & 0.22 & \\
\hline$\gamma$-tocopherol & -0.19 & -0.35 & -0.33 & -0.24 & -0.27 & -0.16 & 0.02 & 0.39 \\
\hline
\end{tabular}

\section{Association of molecular markers with fruit traits}

The stepwise MRA analyses revealed that eight AFLP markers of the 168 polymorphic markers analyzed showed a significant $(\mathrm{P}<0.05)$ association with olive fruit traits (Table 4). EACC/MCTT7 ${ }_{290}$ and EACA/MCAT43 ${ }_{82}$ markers exhibited significant negative correlation with fruit weight $(\mathrm{P}<0.05) . \mathrm{R}^{2}$ for EACC/MCTT7 ${ }_{290}$ and EACA/MCAT43 ${ }_{82}$ markers was 0.385 and 0.709 , respectively. The marker EACA/MCAT43 ${ }_{82}$ also showed a significant negative correlation $(\mathrm{P}<0.05)$ with fruit length, stone weight, and stone length traits. Only one marker (EACC/MCTT2 ${ }_{465}$ ) was found to be significantly associated with fruit width and stone width traits $(\mathrm{P}<0.01)$. The EACC/MCTT11 ${ }_{195}$ marker was also negatively correlated with stone length $\left(\mathrm{R}^{2}=0.741, \mathrm{t}=-2.774, \mathrm{P}<0.05\right)$. The standardized beta coefficient was -0.402 for this marker. For total polyphenols, only one marker (EAGG/MCTC9 ${ }_{246}$ ) exhibited a negative correlation $\left(\mathrm{R}^{2}=0.390, \mathrm{t}=-3.134, \mathrm{P}<0.05\right)$. The standardized beta coefficient was also high (0.842) for this marker. The markers EACC/MCTA3 ${ }_{350}$ and EACA/MCAT24 $4_{192}$ showed significant positive correlations with $\alpha$-tocopherol content of olive oil $(\mathrm{P}<0.01)$. $\mathrm{R}^{2}$ for EACC/MCTA3 ${ }_{350}$ and EACA/MCAT2 $4_{192}$ markers were 0.638 and 0.772 , respectively. On the other hand, there was only one marker (EAGG/MCAA23 ${ }_{199}$ ) that was significantly correlated with $\gamma$-tocopherol content of olive oil with a very high positive correlation value $(0.837)$.

Table 4. Stepwise MRA coefficients and AFLP markers associated with fruit traits.

\begin{tabular}{|c|c|c|c|c|c|c|c|c|c|}
\hline Traits & AFLP markers* & $\begin{array}{l}\text { Standard } \\
\text { error }\end{array}$ & $\begin{array}{c}\text { Standardized } \\
\text { beta coefficients }\end{array}$ & $t$ value & P value & $\mathrm{R}$ & $\mathrm{R}^{2}$ & $\mathrm{R}^{2}$ change & F change \\
\hline \multirow[t]{2}{*}{ Fruit weight (g) } & EACC/MCTT7 ${ }_{290}$ & 1.358 & -0.578 & -3.698 & 0.003 & 0.621 & 0.385 & 0.338 & 8.142 \\
\hline & + EACA/MCAT43 ${ }_{82}$ & 1.501 & -0.571 & -3.653 & 0.003 & 0.842 & 0.709 & 0.660 & 13.346 \\
\hline Fruit width (mm) & EACC/MCTT2 $2_{465}$ & 1.544 & -0.653 & -3.110 & 0.008 & 0.653 & 0.427 & 0.427 & 9.671 \\
\hline Fruit length (mm) & EACA/MCAT43 $3_{82}$ & 1.985 & -0.627 & -3.223 & 0.005 & 0.627 & 0.394 & 0.394 & 10.387 \\
\hline Stone weight $(\mathrm{g})$ & EACA/MCAT43 $3_{82}^{82}$ & 0.158 & -0.555 & -2.669 & 0.017 & 0.555 & 0.308 & 0.308 & 7.122 \\
\hline Stone width (mm) & EACC/MCTT2 $2_{465}^{82}$ & 0.448 & -0.763 & -4.252 & 0.001 & 0.763 & 0.582 & 0.582 & 18.076 \\
\hline \multirow[t]{2}{*}{ Stone length (mm) } & EACA/MCAT43 & 1.164 & -0.674 & -4.648 & 0.000 & 0.767 & 0.588 & 0.588 & 19.980 \\
\hline & + EACC/MCTT11 195 & 1.164 & -0.402 & -2.774 & 0.016 & 0.861 & 0.741 & 0.153 & 7.697 \\
\hline $\begin{array}{l}\text { Total polyphenols } \\
\text { (GAE, } \mathrm{mg} / \mathrm{kg} \text { ) }\end{array}$ & $\mathrm{EAGG} / \mathrm{MCTC}_{246}$ & 52.436 & -0.617 & -3.134 & 0.006 & 0.617 & 0.380 & 0.380 & 9.822 \\
\hline \multirow[t]{2}{*}{$\alpha$-tocopherol $(\mathrm{mg} / \mathrm{kg}$ ) } & EACC/MCTA3 $3_{350}$ & 8.102 & 0.704 & 5.534 & 0.000 & 0.799 & 0.638 & 0.638 & 28.197 \\
\hline & $+{ }^{\mathrm{EACA}} / \mathrm{MCAT}^{350} 4_{192}$ & 8.102 & 0.379 & 2.976 & 0.009 & 0.879 & 0.772 & 0.134 & 8.859 \\
\hline$\gamma$-tocopherol $(\mathrm{mg} / \mathrm{kg})$ & EAGG/MCAA23 ${ }_{199}$ & 3.721 & 0.837 & 6.129 & 0.000 & 0.837 & 0.701 & 0.701 & 37.559 \\
\hline
\end{tabular}

+Indicates the involvement of marker in the preceding step. ${ }^{*}$ Subscript numbers are the estimated sizes of the AFLP markers. 


\section{DISCUSSION}

According to the AFLP dendrogram, all olive cultivars were differentiated from each other below the $75 \%$ similarity level, demonstrating that the genetic variation is high between the olive cultivars and suggesting that this olive collection is a good core collection. However, AFLP markers partially distinguished olive cultivars according to their geographic origin. In some studies, clustering of olive cultivars was found to be correlated with their geographic origin (Claros et al., 2000; Besnard et al., 2001). On the other hand, Fendri et al. (2010) reported that olive cultivars did not group in accordance with their geographical origin. All olive cultivars in the core collection were also distinguished from each other on the basis of cluster analysis with six morphological and three biochemical fruit traits. However, the clustering of olive cultivars with AFLP markers and fruit characteristics was not significantly correlated according to the Mantel test. Low or no correlation between morphological characters and molecular data in olive has also been reported in several studies (Corrado et al., 2009; Rao et al., 2009; Belaj et al., 2011). Contrary to these studies, D'Imperio et al. (2011) found a very high correlation with the Mantel test between morphological and molecular data obtained by evaluating eight SSR markers and 31 morphological descriptors in samples of leaves, drupes and pits of three olive cultivars. The low correlation detected in our study was likely due to the few morphological markers used for the analysis of genetic diversity compared to 168 polymorphic AFLP markers and influence of environmental factors on morphological traits. However, Corrado et al. (2009) stated that the discrimination power of morphological characters was poor in their study even if they used 35 morphological descriptors, and they emphasized the influence of environmental factors on the efficiency of discrimination of morphological characters.

The UPGMA dendrogram based on fruit traits clustered the cultivar Gordales as a distinct group from the other 17 olive cultivars evaluated in this study, where it had the highest morphological fruit characteristic values. In a previous study conducted to evaluate morphological and agronomic characteristics of an olive germplasm collection in Argentina, the olive cultivar Gordal Sevillana with the highest fresh fruit weight and fresh stone weight introduced from Spain was also characterized as a distinct cultivar from other accessions (Trentacoste and Puertas, 2011). The cultivar Gordales evaluated in this study was also introduced from Spain to Turkey, and it may be closely related to Gordal Sevillana.

High correlations were detected between morphological fruit traits evaluated in this study. Similarly, high correlations between morphological fruit traits were reported in several studies in olive (Cantini et al., 1999; León et al., 2004; Belaj et al., 2011). Belaj et al. (2011) determined a high correlation (0.95) between fruit length and stone length in wild olives, which was higher than the value $(0.77)$ found in this study. On the contrary, the correlation between fruit weight and stone weight was higher (0.94) in this study than the result (0.89) of Belaj et al. (2011). The high correlation between the phenotypic traits could make possible the selection of all correlated traits simultaneously by evaluating only one trait during the selection (León et al. 2004).

While four AFLP markers were found to be significantly associated with fruit and stone weight, width and length, four AFLP markers were determined to be highly associated with total polyphenols, $\alpha$-tocopherol and $\gamma$-tocopherol traits in this study. When a morphological trait correlated with another morphological fruit trait, the same AFLP markers were also associated with both traits. For example, EACC/MCTT2 marker was associated with both fruit width and stone width traits and both traits were also significantly correlated. 
Tocopherols are important quality parameters of olive oils and they have high antioxidant activity and health-beneficial effects. The olive cultivars characterized in this study displayed great variation in the content of $\alpha$-tocopherol, which is a precursor of vitamin $\mathrm{E}$, and $\gamma$-tocopherol, considered a superior antioxidant in oil products (Şeker et al., 2008). The quantitative trait loci (QTL) of tocopherols have been mapped in rapeseed (Marwede et al., 2005), but there is no report on mapping of QTL or association of molecular markers with tocopherol content in olive oil to our knowledge. Therefore, these positively and significantly associated markers determined in this study could be useful for the rapid identification of olive genotypes with high $\alpha$-tocopherol and $\gamma$-tocopherol content in olive-breeding programs.

In a similar study, association analysis of SSR and ISSR markers with fruit characteristics in sweet cherry cultivars revealed 14 SSR alleles negatively or positively correlated with different morphological traits by using MRA (Ganopoulos et al., 2011). In addition, three ISSR markers were identified to be correlated with fruit harvest time and soluble solids and four ISSR markers were found to be correlated with fruit skin color. In another recent study on cherries, 38 SSR alleles and 135 RAPD markers were associated with 14 fruit characters using MRA analysis (Khadivi-Khub, 2013). Similarly, four ISSR markers were associated with protein content and four with sugar content by using stepwise MRA in mulberry (Morus spp) (Kar et al., 2008). The association of three ISSR markers with high antioxidant activity in $\mathrm{Va}$ leriana jatamansi was also reported by using simple-regression analysis, and it was suggested that these markers can be utilized for the selection of genotypes with high antioxidant activity in breeding programs (Jugran et al., 2013).

In summary, all olive cultivars were sufficiently differentiated from each other by either AFLP markers or fruit characters. However, clustering of these olive cultivars based on AFLP markers and fruit characters were not in agreement as reported in several previous studies in olive. Neither AFLP markers nor fruit characteristics grouped all olive cultivars according to their geographical origin, suggesting that olive genotypes or cultivars were exchanged between regions or countries without proper passport information. In addition, a high degree of positive correlations between fruit traits was detected. Furthermore, stepwise MRA analysis determined a significant association between eight AFLP markers and morphological and biochemical fruit traits. This is the first report on the association of AFLP markers with fruit traits in olive to our knowledge. Molecular markers associated with morphological and agronomic traits could be utilized for the breeding of olive cultivars. However, the association power of these markers needs to be confirmed in larger populations, and then, highly correlated markers need to be converted to PCR-based DNA marker such as sequence-characterized amplified region markers for better utilization.

\section{ACKNOWLEDGMENTS}

Research supported by the Scientific and Technological Research Council of Turkey (TUBITAK-TOVAG project \#3358). The authors thank General Directorate of Olive Production Station of the Ministry of Agriculture and Rural Affairs, Balikesir, Turkey, for providing the fruit samples of olive cultivars.

\section{REFERENCES}

Affifi AA and Clark V (1984). Computer-Aided Multivariate Analysis. Van Nostrand Reinhold, New York. 
Angiolillo A, Mencuccini M and Baldoni L (1999). Olive genetic diversity assessed using amplified fragment length polymorphisms. Theor. Appl. Genet. 98: 411-421.

Bartolini G, Prevost G, Messeri C and Carignani G (1998). Olive Germplasm: Cultivars and World-Wide Collections. FAO Seed and Plant Genetic Resources Service, Plant Production and Protection Division, Roma.

Belaj A, Satovic Z, Cipriani G, Baldoni L, et al. (2003). Comparative study of the discriminating capacity of RAPD, AFLP and SSR markers and of their effectiveness in establishing genetic relationships in olive. Theor. Appl. Genet. 107: 736-744.

Belaj A, León L, Satovic Z and de la Rosa R (2011). Variability of wild olives (Olea europaea subsp. europaea var. sylvestris) analyzed by agro-morphological traits and SSR markers. Sci. Hortic. 129: 561-569.

Besnard G, Baradat P and Bervillé A (2001). Genetic relationships in the olive (Olea europaea L.) reflect multilocal selection of cultivars. Theor. Appl. Genet. 102: 251-258.

Bogani P, Cavalieri D, Petruccelli R and Roselli G (1994). Identification of olive tree cultivars by using random amplified polymorphic DNA. Acta Hortic. 356: 98-101.

Boskou D (2002). Olive Oil. In: Vegetable Oils in Food Technology Composition, Properties and Uses (Gunstone FD, ed.). CRC Press Blackwell Publishing, Oxford, 244-296.

Cantini C, Cimato A and Sani G (1999). Morphological evaluation of olive germplasm present in Tuscany region. Euphytica 109: 173-181.

Claros MG, Crespillo R, Aguilar ML and Cánovas FM (2000). DNA fingerprinting and classification of geographically related genotypes of olive tree (Olea europaea L.). Euphytica 116: 131-142.

Corrado G, La Mura M, Ambrosino O, Pugliano G, et al. (2009). Relationships of Campanian olive cultivars: comparative analysis of molecular and phenotypic data. Genome 52: 692-700.

D'Imperio M, Viscosi V, Scarano MT and D'Andrea M (2011). Integration between molecular and morphological markers for the exploitation of olive germoplasm (Olea europaea). Sci. Hortic. 130: 229-240.

Dice LR (1945). Measures of the amount of ecologic association between species. Ecology 26: 297-302.

Ercisli S, Barut E and Ipek A (2009). Molecular characterization of olive cultivars using amplified fragment length polymorphism markers. Genet. Mol. Res. 8: 414-419.

Fendri M, Trujillo I, Trigui A and Rodríguez-García IM (2010). Simple sequence repeat identification and endocarp characterization of olive tree accessions in a Tunisian germplasm collection. Hortscience 45: 1429-1436.

Ganopoulos IV, Kazantzis K, Chatzicharisis I and Karayiamis I (2011). Genetic diversity, structure and fruit associations in Greek sweet cherry cultivars using microsatellite (SSR/ISSR) and morpho-physiological markers. Euphytica 181: 237-231.

Gutfinger T (1981). Polyphenols in olive oils. J. Am. Oil Chem. Soc. 58: 966-968.

Ipek A, Barut E, Gulen H, Oz AT, et al. (2009). SSR analysis demonstrates that olive production in the southern Marmara region in Turkey uses a single genotype. Genet. Mol. Res. 8: 1264-1272.

Ipek A, Barut E, Gulen H and Ipek M (2012). Assessment of inter- and intra-cultivar variations in olive using SSR markers. Sci. Agric. 69: 327-335.

Ipek M, Ipek A and Simon PW (2003). Comparison of AFLPs, RAPD markers, and isozymes for diversity assessment of garlic and detection of putative duplicates in germplasm collections. J. Am. Soc. Hortic. Sci. 128: 246-252.

Ipek M, Ipek A, Almquist SG and Simon PW (2005). Demonstration of linkage and development of the first low-density genetic map of garlic, based on AFLP markers. Theor. Appl. Genet. 110: 228-236.

Ipek M, Ipek A and Simon PW (2008). Molecular characterization of Kastamonu garlic: an economically important garlic clone in Turkey. Sci. Hortic. 115: 203-208.

Ipek M, Sahin N, Ipek A, Cansev A, et al. (2015). Development and validation of new SSR markers from expressed regions in the garlic genome. Sci. Agric. 72: 41-46.

Jugran A, Rawat S, Dauthal P and Mondal S (2013). Association of ISSR markers with some biochemical traits of Valeriana jatamansi Jones. Ind. Crop. Prod. 44: 671-676.

Kar PK, Srivastava PP, Awasthi AK and Urs SR (2008). Genetic variability and association of ISSR markers with some biochemical traits in mulberry (Morus spp.) genetic resources available in India. Tree Genet. Genomes 4: 75-83.

Khadivi-Khub A (2013). Regression association analysis of fruit traits with molecular markers in cherries. Plant Syst. Evol. 5: 1163-1173.

la Rosa R, Angiolillo A, Guerrero C, Pellegrini M, et al. (2003). A first linkage map of olive (Olea europaea L.) cultivars using RAPD, AFLP, RFLP and SSR markers. Theor. Appl. Genet. 106: 1273-1282.

León L, Martín LM and Rallo L (2004). Phenotypic correlations among agronomic traits in olive progenies. J. Am. Soc. Hortic. Sci. 129: 271-276.

Marwede V, Gül MK, Becker HC and Ecke W (2005). Mapping of QTL controlling tocopherol content in winter oilseed rape (Brassica napus L.). Plant Breed. 124: 20-26. 
Owen CA, Bita EC, Banilas G, Hajjar SE, et al. (2005). AFLP reveals structural details of genetic diversity within cultivated olive germplasm from the Eastern Mediterranean. Theor. Appl. Genet. 110: 1169-1176.

Rallo P, Dorado G and Martín A (2000). Development of simple sequence repeats (SSRs) in olive tree (Olea europaea L.). Theor. Appl. Genet. 101: 984-989.

Rao R, La Mura M, Corrado G and Ambrosino O (2009). Molecular diversity and genetic relationships of southern Italian olive cultivars as depicted by AFLP and morphological traits. J. Hortic. Sci. Biotechnol. 84: 261-266.

Rotondi A, Magli M, Ricciolini C and Baldoni L (2003). Morphological and molecular analyses for the characterization of a group of Italian olive cultivars. Euphytica 132: 129-137.

Sefc KM, Lopes S, Mendonça D and Dos Santos MR (2000). Identification of microsatellite loci in olive (Olea europaea) and their characterization in Italian and Iberian olive trees. Mol. Ecol. 9: 1171-1173.

Şeker M, Gül MK, İpek M, Toplu C, et al. (2008). Screening and comparing tocopherols in the rapeseed (Brassica napus L.) and olive (Olea europaea L.) varieties using high-performance liquid chromatography. Int. J. Food Sci. Nutr. 59: 483-490.

Sneath PHA and Sokal RR (1973). Numerical Taxonomy. Freeman, San Francisco.

Taamalli W, Geuna F, Banth R and Bassi D (2006). Agronomic and molecular analyses for the characterization of accessions in Tunisian olive germplasm collections. Electron. J. Biotechnol. 9: 467-481.

Tohme J, Gonzalez DO, Beebe S and Duque MC (1996). AFLP analysis of gene pools of a wild bean core collection. Crop Sci. 36: 1375-1384.

Trentacoste ER and Puertas CM (2011). Preliminary characterization and morpho-agronomic evaluation of the olive germplasm collection of the Mendoza province (Argentina). Euphytica 177: 99-109.

Virk PS, Ford-Lloyd BV, Jackson MT and Pooni HS (1996). Predicting quantitative variation within rice germplasm using molecular markers. Heredity 76: 296-304.

Vos P, Hogers R, Bleeker M, Reijans M, et al. (1995). AFLP: a new technique for DNA fingerprinting. Nucleic Acids Res. 23: 4407-4414. 